\title{
INFLUENCE OF HESPERIDIN APPLICATION ON BONDING OF RESIN MODIFIED GLASS IONOMER-BASED RESTORATIVE MATERIAL TO DENTIN TREATED WITH OXYGEN INDUCED ENDODONTIC IRRIGANTS
}

\author{
Tarek Ahmed Soliman* and Sayed Ghorab*
}

\begin{abstract}
Objectives: To investigate the effect of hesperidin application on the bonding of resin-modified glass ionomer-based restorative material to dentin treated with oxygen-induced endodontic irrigants.

Materials and Methods: One hundred human permanent molars were categorized into five groups ( $n=20$ /group), treated with various irrigants as follows: group $\mathrm{C}$; distilled water (negative control), group SH; $5.25 \% \mathrm{NaOCl}$ (positive control), group $\mathrm{SH}+\mathrm{H} ; 5.25 \% \mathrm{NaOCl}+5 \%$ hesperidin, group $\mathrm{HP} ; 10 \% \mathrm{H}_{2} \mathrm{O}_{2}$, group $\mathrm{HP}+\mathrm{H} ; 10 \% \mathrm{H}_{2} \mathrm{O}_{2}+5 \%$ hesperidin. Immediately after treatments, the specimens were bonded with the RMGI-based restorative material. For each group, half of the specimens were evaluated for $\mu$ SBS by a universal testing machine and the other half for elemental analysis by EDX. Additional ten specimens ( $n=2 /$ group) were prepared for the micromorphological analysis using SEM. Data were analyzed using One-way ANOVA and Tukey's multiple comparison test $(P<.05)$. The fracture pattern was analyzed by the Chi-square $\left(\chi^{2}\right)$ test.
\end{abstract}

Results: Hesperidin groups improved the $\mu \mathrm{SBS}$, with a significant effect for $\mathrm{HP}+\mathrm{H}$ group $(\mathrm{P}<.05)$. A significant increase in the ion weight percentages was detected in hesperidin groups $(\mathrm{P}<.001)$.

Conclusion: Application of hesperidin improved the dentin bond strength and increased the ion weight percentages in dentin alongside RMGI based restorative material; this could be a promising approach to aid dental practitioners in their decisions, regarding which restorative material to use especially in caries susceptible patients.

KEYWORDS: Elemental analysis; Hesperidin; Microshear bond strength

\section{INTRODUCTION}

Immediate restoration of endodontically treated teeth is clinically important to prevent bacte- rial leakage from oral cavity, to withstand occlusal force, and to avoid fracture of remaining tooth structure. ${ }^{1}$ Core buildup restorative materials have

* Dental Biomaterials Department, Faculty of Dentistry, Mansoura University, Mansoura, Egypt 
been widely used especially when using the prefabricated posts in the endodontically treated teeth. These materials include three main groups: silver amalgam, resin composite, and resin modified glass ionomer (RMGI). ${ }^{2}$ RMGI-based restorative materials consider many advantages such as; thermal expansion similar to tooth structure, decreased microleakage, chemical bonding to tooth structure and fluoride release. ${ }^{3,4}$ RMGI primer is a light-cured liquid, designed for resin-modified glass ionomerbased restorative material and applied before placement of the restoration to modify the smear layer and adequately wet the tooth surfaces to facilitate the adhesion.-5

Sodium hypochlorite $(\mathrm{NaOCl})$ and hydrogen peroxide $\left(\mathrm{H}_{2} \mathrm{O}_{2}\right)$ are well known as endodontic irrigants due to their antibacterial and de-proteinization effects..$^{6-8}$ Nevertheless, these irrigants could change the dentin composition and affect its interaction with the restorative materials. Previous studies stated that dentin bond strength could be negatively affected by $\mathrm{NaOCl}$ application. ${ }^{9-13}$ However, other studies showed neutral ${ }^{14-16}$ or even positive results ${ }^{17-20}$ depending on the application time and the adhesive type. If the bond strength was decreased because of the oxidizing effects of these irrigants, utilizing a biocompatible antioxidant before resin bonding may reverse this reaction. ${ }^{10}$

Hesperidin (HPN), is a flavonoid extracted from citrus fruits. HPN yields a wide range of benefits such as: anti-inflammatory, anti-microbial, collagen cross-linker, resistance to caries progression, promotion of the remineralization process and antioxidant effects. ${ }^{21-23}$ There is lack of information regarding the effect of hesperidin on the interaction between RMGI- based restorative material and the dentin treated with oxygen-induced endodontic irrigants. Accordingly, the primary rationale of this study was to assess the impact of hesperidin application on the bonding of RMGI-based restorative material to dentin treated with oxygen- induced endodontic irrigants. In addition, to determine if the application of HPN has an effect on the chemical structure change of dentin along side RMGI based restorative material. The null hypotheses for this study were that; the use of HPN has no effect (1) on the bond strength and (2) on the chemical structure of $\mathrm{NaOCl}$ or $\mathrm{H}_{2} \mathrm{O}_{2}$ treated dentin bonded to RMGI based restorative material.

\section{MATERIALS AND METHODS}

RMGI-based restorative material (Vitremer; 3M; St Paul, MN, USA) and a $5 \%$ hesperidin solution (Sigma-Aldrich;St. Louis, MO, USA) were the materials used in this study. The chemical compositions of the materials are presented in table 1 .

\section{Study Design}

One hundred sound, non-carious human permanent molars were used for $\mu$ SBS testing $(n=50)$ and for elemental analysis $(n=50)$. For each test, the teeth were subdivided into five groups ( $\mathrm{n}=10$ /group) according to the type of irrigants used. Additional ten teeth ( $n=2 /$ group) were used for the micro-morphological analysis of the bonded interface.

\section{Preparation and Grouping of Specimens}

Fifty sound, extracted human non-carious permanent molars were collected and stored in $0.5 \%$ chloramine $\mathrm{T}$ solution at $4^{\circ} \mathrm{C}$ for less than 4 wks. The crowns were sectioned $1 \mathrm{~mm}$ apical to CEJ. The occlusal one-third were grounded to expose a flat dentin surface using a water-cooled low speed saw (ISOMET, Techcut4, Allied, USA). The flat dentin surfaces were wet polished using 600-grit silicon carbide paper to attain a standardized smear layer. The dentin specimens were then embedded in acrylic resin blocks leaving their occlusal surfaces exposed to various types of irrigants and bonding.

Specimens were randomly assigned into five groups $(n=10)$ according to the various types of 
TABLE (1) Materials used in the study

\begin{tabular}{|c|c|c|}
\hline Materials & Composition & Manufacturer/Lot no \\
\hline $\begin{array}{l}\text { Vitremer: powder/ liquid } \\
\text { (RMGI-based-restorative } \\
\text { material) }\end{array}$ & $\begin{array}{l}\text { Primer: Polyacrylic acid, modified with grafted pendant HEMA } \\
\text { groups, 2-HEMA, ethanol, photocuring initiators. } \\
\text { Powder: Fluoroaluminosilicate glass ( } 70 \mathrm{wt} \% \text { ), potassium persulphate } \\
\text { and ascorbic acid (patented catalyst system), benzoyl peroxide. } \\
\text { Liquid: A copolymer of polymaleic acid and HEMA* = polyacrylic } \\
\text { acid modified with grafted pendant HEMA groups }(15 \mathrm{wt} \%), 2- \\
\text { HEMA ( } 5 \text { w\%), water }(8 \mathrm{wt} \%) \text {, camphorquinone, photoinitiator } \\
\text { (microencapsulated water-soluble ascorbic acid/potassium persulfate). }\end{array}$ & $\begin{array}{l}\text { (3M; St Paul, MN, } \\
\text { USA) / N703302 }\end{array}$ \\
\hline Hesperidin powder $\geq 80 \%$ & Hesperetin-7-O-rutinoside is a flavonoid extracted from citrus fruits. & $\begin{array}{l}\text { (Sigma-Aldrich;St. } \\
\text { Louis, MO, USA) / } \\
\text { SLBT3541 }\end{array}$ \\
\hline
\end{tabular}

irrigants used as follows: group C: irrigated with distilled water for $30 \mathrm{sec}$ (negative control); group SH: irrigated with $5.25 \% \mathrm{NaOCl}$ (positive control) (Chlora Extra; CERKAMED, Kwiatkowskiego, Stalowa Wola, Polska) for $30 \mathrm{sec}$ and then rinsed with distilled water for $30 \mathrm{sec}$; group $\mathrm{SH}+\mathrm{H}$ : irrigated with $5.25 \% \mathrm{NaOCl}$ for $30 \mathrm{sec}$, rinsed with distilled water for $30 \mathrm{sec}$, and then rinsed with 5 $\%$ HPN solution for $10 \mathrm{~min}$; group HP: irrigated with $10 \% \mathrm{H}_{2} \mathrm{O}_{2}$ (Dimamedical, Cairo, Egypt) for $30 \mathrm{sec}$ and then rinsed with distilled water for 30 sec; group $\mathrm{HP}+\mathrm{H}$ : irrigated with $10 \% \mathrm{H}_{2} \mathrm{O}_{2}$ for 30 $\mathrm{sec}$, rinsed with distilled water for $30 \mathrm{sec}$, and then rinsed with 5\% HPN solution for $10 \mathrm{~min}$. The 5\% HPN solution was prepared by adding 5 gm of HPN powder in $100 \mathrm{ml}$ of dimethyle sulfoxide (Fisons Equipment; Bishop Meadow Road, Loughborough, UK) under supervision of the Faculty of Pharmacy, Mansoura University.

\section{Bonding Procedures}

Following the treatment procedures, RMGIbased restorative material was applied according to the manufacturer's instructions: the primer was applied for $30 \mathrm{sec}$, followed by $15 \mathrm{sec}$ of airdrying. Cylinders were cut from tygon tubes $1 \mathrm{~mm}$ diameter and $2 \mathrm{~mm}$ height (Norton Performance Plastic; Cleveland, OH, USA) and mounted on the dentin surface to restrict the bonding area. ${ }^{11}$ The primer was cured for $20 \mathrm{sec}$ using Elipar FreeLight 2 (3M; St Paul, MN, USA, light output: 1226 mW/ $\mathrm{cm}^{2}$ ). The RMGI-based restorative material was manipulated in $2.5: 1 \mathrm{P} / \mathrm{L}$ ratio, packed into the tygon tubes using disposable tips and a syringe and light cured for $40 \mathrm{~s}$. A surgical blade was used to remove the tygon tubes. The specimens were then coated with a protective varnish (Ketac glaze; 3M; St Paul, $\mathrm{MN}, \mathrm{USA}$ ) prior to storage in distilled water at $37^{\circ}$ $\mathrm{C}$ for $24 \mathrm{hrs}$.

\section{Microshear Bond Strength ( $\mu \mathrm{SBS})$ Test}

The microshear bond strength was measured using a universal testing machine (Lloyd Instruments; Fareham, UK). A wire loop with $0.2 \mathrm{~mm}$ diameter was inserted and gently flushed around RMGI/ dentin interface through half of its circumference. The RMGI/dentin interface and the wire loop were aligned as straight as possible to the load cell of the 
testing machine. The shear force was applied at a crosshead speed of $0.5 \mathrm{~mm} / \mathrm{min}$ until failure occurred. ${ }^{24}$ The de-bonded specimens were inspected under an optical stereomicroscope (Olympus SZ61, Tokyo, Japan) at $20 \mathrm{x}$ magnification to determine the mode of failure, either cohesive in RMGI, mixed or adhesive failure.

\section{Micro-morphological Examination of theBond- ed Interface}

Ten additional specimens ( $\mathrm{n}=2 /$ group) were prepared, treated as previously mentioned in $\mu$ SBS testing and restored with the RMGI-based restorative material. The specimens were then sectioned perpendicular to the bonded interface. Successive grits $(600,800$, and 1200-grit) of wet silicon carbide papers were used to polish the cut surfaces. The polished surfaces were then immersed in $10 \%$ phosphoric acid, followed by $5 \% \mathrm{NaOCl}$ for $5 \mathrm{~min}$ and cleaned ultrasonically in distilled water. ${ }^{25}$ The specimens were air-dried, gold sputteredcoated and inspected under the SEM (JSM-6510LV, JOEL, Tokyo, Japan) with $15 \mathrm{KV}$ accelerating voltages (ACCV) at original magnification $2000 \mathrm{x}$. The RMGI primer/dentin interface was evaluated regarding the presence or absence of smear layer, hybrid layer formation and resin tubular penetration.

\section{Elemental Analysis}

An end cutting diamond bur was used to prepare occlusal cavities $(2 \mathrm{~mm}$ in diameter and 1 $\mathrm{mm}$ depth in dentin) in fifty sound, extracted noncarious permanent molar. A nail varnish was used to coat all surfaces except the cavity preparations. The specimens were then assigned into five groups, treated in the same manner as for $\mu$ SBS testing and restored with the RMGI-based restorative material. After that, the specimens were stored in a separate $5 \mathrm{ml}$ vial containing distilled water at $37^{\circ} \mathrm{C}$ for two wks. ${ }^{26}$ The specimens were then sectioned through the center of the restoration in a bucco-lingual direction using a low-speed diamond disc under water-cooling. Successive grits of wet silicon carbide papers $(600,800$, and 1200-grit) were used to polish the sectioned halves. The polishing was then completed using a lapping diamond paste. The specimens were placed on stainless steel stubs and examined by the energy dispersive X-ray (EDX). The weight percentages of fluoride, strontium, silicon, and aluminum ions were calculated axially in close vicinity to the adhesive-restoration/tooth interface. ${ }^{27}$ Three readings of ions weight percentages were averaged to get one from each specimen.

\section{Statistical Analysis}

The $\mu \mathrm{SBS}$ values and ion weight percentages were first checked by the Shapiro-Wilk test for the normal distribution of data and then analyzed using One-way ANOVA and Tukey's multiple comparison test $(P<.05)$. The fracture pattern was analyzed by the Chi-square $\left(\chi^{2}\right)$ test.

\section{RESULTS}

\section{Microshear Bond Strength ( $\mu \mathrm{SBS})$}

The mean and standard deviations of the $\mu$ SBS values $(\mathrm{MPa})$ are presented in Table 2 . A significant difference was recorded between the different groups $(P<.001)$. The Tukey's multiple comparison test showed that, the $\mu \mathrm{SBS}$ was improved after hesperidin application with only significant effect in $\mathrm{HP}+\mathrm{H}$ group $(\mathrm{SH}+\mathrm{H}$ group, $P=$ 0.076 and $\mathrm{HP}+\mathrm{H}$ group, $P<.001)$. There was no significant difference between $\mathrm{SH}$ and HP groups $(P=$ $.49)$ or in between $\mathrm{SH}$ and $\mathrm{SH}+\mathrm{H}(P=.07)$. Figure 1 showed the fracture analysis for each group. Mixed failure was the predominant type $\left(\chi^{2}=10.7, P=.03\right)$ in all groups except group $\mathrm{C}$, whereas the adhesive failure was the most significant one in this group $\left(\chi^{2}=20.37, P=.004\right)$. 
TABLE (2) microshear bond strength (Mean \pm SD) in MPa for the different groups

\begin{tabular}{ll}
\hline Groups & $\boldsymbol{\mu S B S}($ Mpa) Means \pm SD \\
\hline $\mathrm{C}$ & $7.46 \pm 2.38^{\mathrm{e}}$ \\
$\mathrm{SH}$ & $11.37 \pm 2.31^{\mathrm{cd}}$ \\
$\mathrm{SH}+\mathrm{H}$ & $14.95 \pm 2.80^{\mathrm{bc}}$ \\
$\mathrm{HP}$ & $13.29 \pm 2.74^{\mathrm{cd}}$ \\
$\mathrm{HP}+\mathrm{H}$ & $20.69 \pm 3.07^{\mathrm{a}}$ \\
\hline
\end{tabular}

$C$ : distilled water (negative control); $\mathrm{SH}$ : sodium hypochlorite (positive control); $\mathrm{SH}+\mathrm{H}$ :sodiumhypo chlorite+hespiridin; $\mathrm{HP}$ :hydrogen peroxide; $\mathrm{HP}+\mathrm{H}$ : hydrogen peroxide+hespiridin.

Groups identified by different superscript lowercase letters are significantly different $(P<.05)$

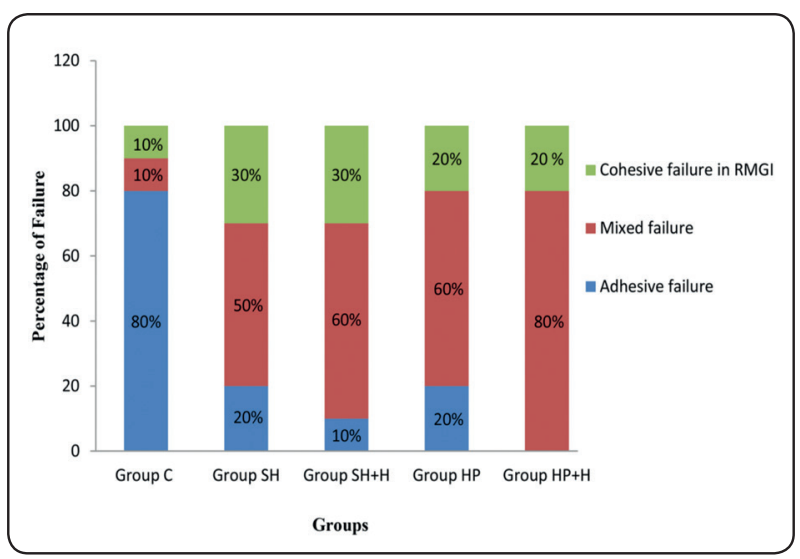

Fig. (1) Percentages of failure modes for the different groups
Micro-morphological Analysis of the Bonded Interface

SEM images of dentin/RMGI primer interface are presented in Figure 2. The microscopic evaluations showed wide variations between the groups. Hesperidin groups showed more tubular penetration by RMGI primer. Formation of the thick hybrid layer (between arrows) could be observed in all groups (A,B,C,D and E). The deepest part of the smear layer (star) could be seen only in $C$ group (fig.2A). Regarding the RMGI primer tubular penetration, there was no penetration in $\mathrm{C}$ group (fig.2A), limited penetration in SH group (fig.2B), more penetration in HP group (fig.2D). After application of hesperidin, the tubular penetration was enhanced in $\mathrm{SH}+\mathrm{H}$ group and $\mathrm{HP}+\mathrm{H}$ groups (fig. 2C and E). Nevertheless, there is a disruption along its length in $\mathrm{SH}+\mathrm{H}$ group (fig. $2 \mathrm{C}$ ). A complete penetration without disruption was observed in $\mathrm{HP}+\mathrm{H}$ group (fig. 2E). Hand pointer showed the different configurations of RMGI primer tubular penetration..

\section{Elemental Analysis}

The ion weight percentages (means and standard deviations) of fluoride, strontium, silicon, and aluminum are presented in Table 3. Significant differences $(P<.001)$ were detected for each element among the tested groups. A significant increase in ion weight percentages was detected in hesperidin groups $(\mathrm{SH}+\mathrm{H}$ and $\mathrm{HP}+\mathrm{H})$ in comparison to $\mathrm{C}, \mathrm{SH}$ and HP groups $(P<.001)$. 

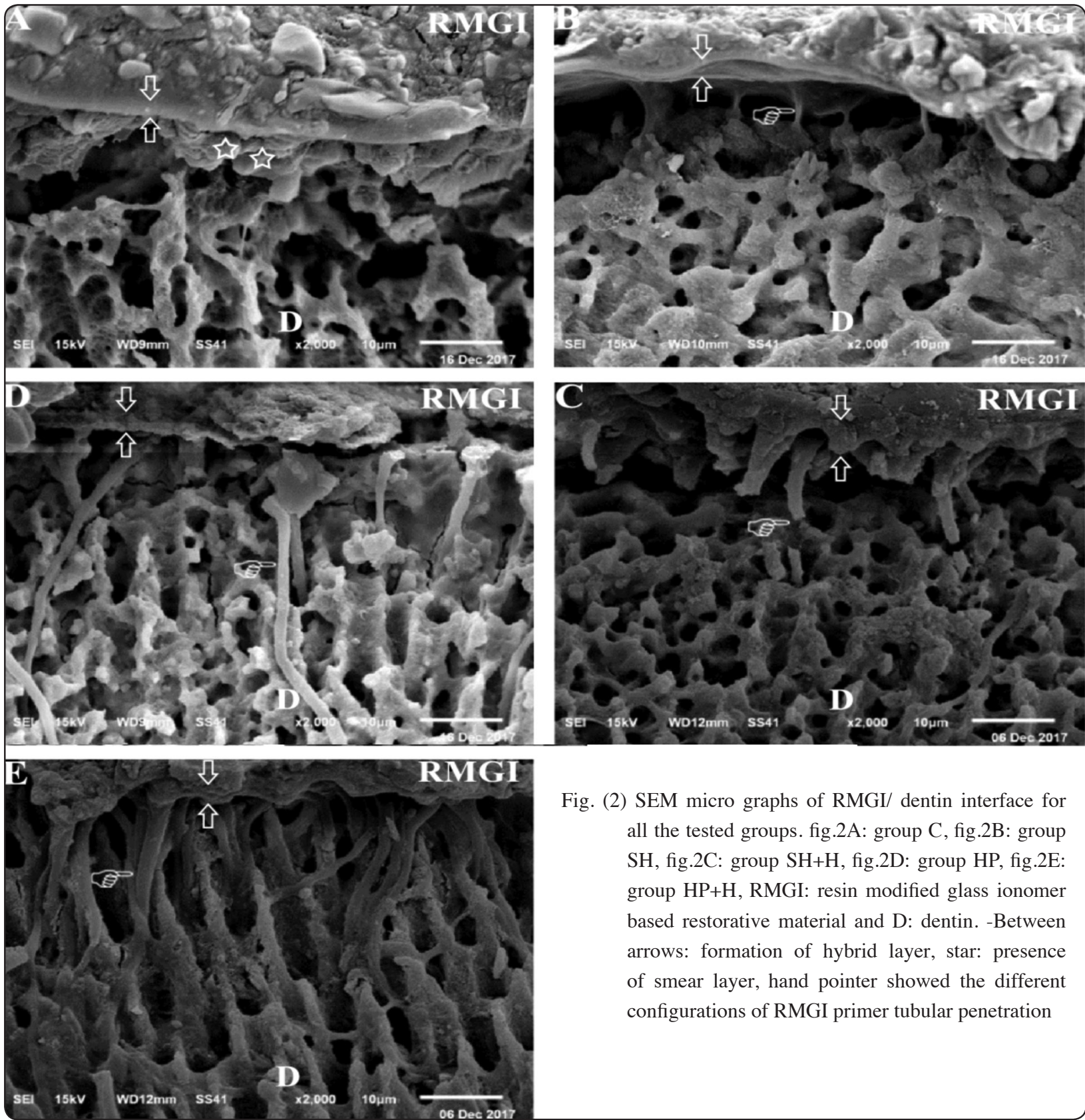

RMGE

Fig. (2) SEM micro graphs of RMGI/ dentin interface for all the tested groups. fig.2A: group $\mathrm{C}$, fig.2B: group $\mathrm{SH}$, fig.2C: group $\mathrm{SH}+\mathrm{H}$, fig.2D: group HP, fig.2E: group $\mathrm{HP}+\mathrm{H}$, RMGI: resin modified glass ionomer based restorative material and D: dentin. -Between arrows: formation of hybrid layer, star: presence of smear layer, hand pointer showed the different configurations of RMGI primer tubular penetration

TABLE (3) Mean and SD of ion Wt \% for fluoride, strontium, silicon, and aluminumin dentin

\begin{tabular}{lcccc}
\hline Groups & $\begin{array}{c}\text { Fluoride } \\
\text { Mean } \pm \text { SD }\end{array}$ & $\begin{array}{c}\text { Strontium } \\
\text { Mean } \pm \text { SD }\end{array}$ & $\begin{array}{c}\text { Silicon } \\
\text { Mean } \pm S D\end{array}$ & $\begin{array}{c}\text { Aluminum } \\
\text { Mean } \pm \text { SD }\end{array}$ \\
\hline C & $0.00 \pm 0.00^{\mathrm{e}}$ & $0.00 \pm 0.00^{\mathrm{e}}$ & $0.00 \pm 0.00^{\mathrm{e}}$ & $0.33 \pm 0.01^{\mathrm{cd}}$ \\
$\mathrm{SH}$ & $1.86 \pm 0.05^{\mathrm{b}}$ & $0.57 \pm 0.03^{\mathrm{c}}$ & $0.15 \pm 0.02^{\mathrm{d}}$ & $0.41 \pm 0.01^{\mathrm{c}}$ \\
$\mathrm{SH}+\mathrm{H}$ & $2.13 \pm 0.04^{\mathrm{a}}$ & $0.69 \pm 0.01^{\mathrm{ab}}$ & $0.98 \pm 0.05^{\mathrm{b}}$ & $0.62^{\mathrm{b}} \pm 0.02^{\mathrm{b}}$ \\
$\mathrm{HP}$ & $1.09 \pm 0.06^{\mathrm{d}}$ & $0.51 \pm 0.02^{\mathrm{d}}$ & $0.25 \pm 0.04^{\mathrm{c}}$ & $0.32 \pm 0.02^{\mathrm{cd}}$ \\
$\mathrm{HP}+\mathrm{H}$ & $1.34 \pm 0.07^{\mathrm{c}}$ & $0.71 \pm 0.03^{\mathrm{a}}$ & $1.63 \pm 0.04^{\mathrm{a}}$ & $0.79 \pm 0.01^{\mathrm{a}}$ \\
\hline
\end{tabular}

Groups identified by different lowercase letters are significantly different $(P<.05)$ 


\section{DISCUSSION}

In this study, $\mathrm{NaOCl}$ and $\mathrm{H}_{2} \mathrm{O}_{2}$ were used as irrigants for $30 \mathrm{~s}$ as it has been reported that; $30 \mathrm{~s}$ irrigation by $5.25 \% \mathrm{NaOCl}$ eliminate Enterococcus faecalis, which is the most resistant microorganism in root canal. ${ }^{28}$ HPN was dissolved in dimethyl sulfoxide solutionas it has a low solubility in water. ${ }^{29}$ A 5\% HPN solution was used in this study, as a 5\% HPN-containing primer had been reported to improve the immediate bond strength and preserve the bonding durability. ${ }^{30,31}$ The microshear testing was used in this study. It controls the bonded area and eliminates the pre-stressing factors, such as specimens sectioning, which is performed in the microtensile bond strength test. ${ }^{32,33}$ In the current study, superficial, sound, and flat dentin surfaces were used as dentin substrate, as it has been reported in other studies. ${ }^{32-34}$

The effect of $\mathrm{NaOCl}$ and $\mathrm{H}_{2} \mathrm{O}_{2}$ on the dentin bond strength showed conflict outcomes as either increased ${ }^{17-20}$, decreased ${ }^{9-13}$ or even neutral ${ }^{14-}$ 16 results. In the current study, SH and HP groups showed significantly higher $\mu$ SBS than group C. This could be attributed to the tubular penetration by RMGI primer and formation of resin tags in $\mathrm{SH}$ and HP groups (Figs 2B and 2D) respectively. On the other hand, no tubular penetration was observed in group $\mathrm{C}$ (Fig 2A). These results are in accordance with the previous studies, which stated that; $\mathrm{NaOCl}$ and $\mathrm{H}_{2} \mathrm{O}_{2}$ deproteinize the smear layer-covered dentin by dissolving its organic phase giving rise to an appropriate substrate for bonding..$^{17-20}$ However, other studies reported that, application of $\mathrm{NaOCl}$ or $\mathrm{H}_{2} \mathrm{O}_{2}$ for 10 minutes could negatively affect the dentin bond strength due to their oxidative property to dentin collagen matrix. ${ }^{9,12,13,35}$ Therefore, the effect of oxygen induced endodontic irrigants depends on the application time.

The first null hypothesis that application of hesperidin has no effect on the bond strength of $\mathrm{NaOCl}$ or $\mathrm{H}_{2} \mathrm{O}_{2}$ treated dentin bonded to RMGI based restor- ative material was rejected since, HPN improved the $\mu \mathrm{SBS}$,with significant effect in $\mathrm{HP}+\mathrm{H}$ group. HPN enhances the cross linking of type I collagen in dentin, which is an essential step in improving the adhesion. ${ }^{21,22,30,31}$ The pyridinoline crosslinks in type I collagen could be disrupted by $\mathrm{NaOCl}$ not by $\mathrm{H}_{2} \mathrm{O}_{2} .{ }^{36}$ Accordingly, HPN could not significantly improve the bond strength of $\mathrm{SH}+\mathrm{H}$ group. This clarification might be supported through the widespread tubular penetration by RMGI primer in $\mathrm{HP}+\mathrm{H}$ group (fig.2E). However, the tubular penetration was disrupted in $\mathrm{SH}+\mathrm{H}$ group (fig.2C). The fracture analysis showed that, mixed failure was the predominant type in all groups except in group C. The high percentages of mixed failure, especially in $\mathrm{HP}+\mathrm{H}$ group could be attributed to the better bonding between the primer and dentin substrate and the weak cohesive strength of RMGI material.$^{37}$

Elemental analysis was assessed by energy dispersive $\mathrm{x}$-ray (EDX) since it is both a sensitive and an accurate detecting method used to analyze the chemical composition and distribution of various elements. ${ }^{38}$ The weight percentages of fluoride, strontium, aluminum, and silicon ions were investigated in this study since it has been proven that these ions released and exchanged at the tooth interface. ${ }^{39,40}$ Moreover, these ions are able to enhance the remineralization adjacent to the tooth/ restoration interface. ${ }^{41}$ Hesperidin groups showed an increase in the weight percentages of these ions, which could enhance the remineralization process. The results of the current study are in agreement with a previous study ${ }^{42}$ which stated that HPN might have the potential to promote the remineralization process through increasing dentin ion uptake. Accordingly, the second null hypothesis was rejected

One of the limitation of this study is that it does not undergo aging to test the durability of the bond strength data. In addition, the clinical performance assessment is required to provide reliable 
recommendations for this in vitro study.

Within the limitation of this study, by combining the outcomes from the $\mu$ SBS, the micromorphological and elemental analysis, application of hesperidin improved the dentin bond strength and increased the ion weight percentages in dentin along side RMGI based restorative material; this could be a promising approach to aid dental practitioners in their decisions, regarding which restorative material to use especially in caries susceptible patients.

\section{REFERENCES}

1. Ausiello P, Degee AJ, Rengo S, Davidson CL. Fracture resistance of endodontically treated premolars adhesively resotored. Am J Dent 1997; 10:237-41.

2. Moon MG, Jarrett TA, Morlen RA, Fallo GJ. The effect of various base/core materials on the setting of a polyvinyl siloxane impression material. J Prosthet Dent 1996, 76:608-12.

3. Roberts HW, Berzins DW, Charlton DG. Hardness of three resin-modified glass-ionomer restorative materials as a function of depth and time. J esthet Restor Dent 2009; 21:262-72

4. Mount GJ, Patel C, Makinson OF. Resin modified glass ionomers: strength, cure depth and translucency. Aust Dent J 2002; 47:339-43.

5. Gleicher H, Fuks AB, Sela J. Adaptation of Class II Vitremer restorations with and without primer: a morphometric study. Pediatr Dent 1998; 20:263-66.

6. Farina AP, Cecchin D, Barbizam JV, Carlini-ju'nior B. Influence of endodontic irrigants on bond strength of a self-etching adhesive. Aust Endod J 2011; 37:26-30.

7. Santos JN, Carrilho MR, DE Goes MF, Zaia AA, Gomes BP, Souza-Filho FJ, Ferraz CC. Effect of chemical irrigants on the bond strength of a self-etching adhesive to pulp chamber dentin. J Endod 2006; 32:1088-90.

8. Ozturk B, Ozer F. Effect of $\mathrm{NaOCl}$ on bond strengths of bonding agents to pulp chamber lateral walls. J Endod 2004; 30:362-65.

9. Lai SC, Mak YF, Cheung GS, Osorio R, Toledano M, Carvalho RM, Tay FR, Pashley DH. Reversal of compromised bonding to oxidized etched dentin. J Dent Res 2001; 80: 1919-24.
10. Prasansuttiporn T, Nakajima M, Kunawarote S, Foxton RM, Tagami J. Effect of reducing agents on bond strength to $\mathrm{NaOCl}$ treated dentin. Dent Mater 2011; 27:229-34.

11. Fawzi EM, Elkassas DW, Ghoneim AG. Bonding strategies to pulp chamber dentin treated with different endodontic irrigants: microshear bond strength testing and SEM analysis. J Adhes Dent 2010; 12:63-70.

12. Gönülol N, Glu EK, Ertas E. Effect of sodium ascorbate on dentin bond strength after treatment with oxidizing root canal irrigants. JDS 2015; 10:139-44.

13. Vongphan N, Senawongse P, Somsiri W, Harnirattisai C. Effects of sodium ascorbate on microtensile bond strength of total-etching adhesive system to $\mathrm{NaOCl}$ treated dentine. J Dent 2005; 33:689-95.

14. Gwinnett AJ. Altered tissue contribution to interfacial bond strenth with acid conditioned dentin. Am J Dent 1994; 7:243-46.

15. Armstrong SR, Boyer DB, Keller JC, Park JB. Effect of hybrid layer on fracture toughness of adhesively bonded dentin-resin composite joint. Oper Dent 1997; 22:159-66.

16. Coli P, Alaeddin S, Wennerberg A, Karlsson S. In vitro dentin pretreatment: surface roughness and adhesive shear bond strength. Eur J Oral Sci 1999; 107:400-13.

17. Saboia VP, Rodrigues AL, Pimenta LA. Effect of collagen removal on shear bond strength of two single-bottle adhesive systems. Oper Dent 2000; 25:395-400.

18. Wakabayashi Y, Kondou Y, Suzuki K, ET Yamashita A. Effect of dissolution of collagen on adhesion to dentin. Int J Prosthodont 1994; 7:302-6.

19. Inai N, Kanemura N, Tagami J, Watanabe LG, Marshall SJ, Marshall GW. Adhesion between collagen depleted dentin and dentin adhesive. Am J Dent 1998; 11:123-7.

20. Phrukkanon S, Burrow MF, Hartley PG, Tyas MJ. The influence of the modification of etched bovine dentin on bond strengths. Dent Mater 2000; 16:255-65.

21. Hiraishi N, Sono R, Islam MS, Otsuki M, Tagami J, Takatsuka T. Effect of hesperidin in vitro on root dentine collagen anddemineralization. J Dent 2011; 39:391-6.

22. Islam SM, Hiraishi $\quad \mathrm{N}$, Nassar $\quad \mathrm{M}$, Sono $\mathrm{R}$, Otsuki M, Takatsura T, Yiu C, Tagami J. In vitro effect of hesperidin on root dentin collagenand de/re-mineralization. Dent Mater J 2012; 31:362-7.

23. Trzeciakiewicz A, Habauzit V, Mercier S, Barron D, Urpi- 
Sarda M, Manach C. Molecular mechanism of hesperetin7-O-glucuronide, the main circulatingmetabolite of hesperidin, involved in osteoblast differentiation. J Agric Food Chem 2010; 58:668-75.

24. Mcdonough WG, Antonucci JM, He J, Shimada Y, Chiang MY, Schultheisz C. A microshear test to measure bond strengths of dentin- polymer interface. Biomaterials 2002; 23:3603-8.

25. Hammama HH, Burrow MF, Yiu C. Effect of dentine conditioning on adhesion of resin modified glass ionomer adhesives. Aust Dent J 2014; 59:193-200.

26. Knight GM, Mclntyre JM, Craig GC, Mulyani. Ion uptake into demineralized dentine from glass ionomer cement following pretreatment with silver flouride and potassium iodide. Aust Dent J 2006; 51:237-41.

27. Mass E, Hassan A, Cohen O, Ziberman U. Long-term invivo effect of various restorative materials on enamel and dentin of primary molars. Quintessence Int 2017; 48:633638.

28. Gomes BP, Ferraz CC, Vianna ME, Filho FJ. In vitro antimicrobial activity of several concentrations of sodium hypochlorite and chlorhexidine gluconate in the elimination of Enterococcus faecalis. Int Endod J 2001; 34:424-428.

29. Magwaza LS, Opara UL, Cronje PJ, Landahl S, Ortiz JO, Terry AL. Rapid methods for extracting and quantifying phenolic compounds in citrus rinds. Food Sci Nutr. 2015; 4:4-10.

30. Islam MS, Hiraishi N, Nassar M, Yiu C, Otsuki $\mathrm{M}$, Tagami J. Effect of hesperidin incorporation into aselfetching primer on durability of dentin bond. Dent Mater 2014; 30: 1205-12.

31. Islam S, Hiraishi N, Nassar M, Yiu C, Otsuki M, Tagami J. Effect of natural cross-linkers incorporation in a self-etchingprimer on dentine bond strength. J Dent 2012;40:1052-59.

32. Armstrong S, Geraldeli S, Maia R, Raposo LH, Soares CJ, Yamagawa J. Adhesion to tooth structure: a critical review of "micro" bond strength test methods. Dent Mater 2010; 26:50-62.
33. Scherrer SS, Cesar PF, Swain MV. Direct comparison of the bond strength results of the different test methods: a critical literature review. Dent Mater 2010; 26:78-93.

34. Nikaido T, Takano Y, Sasafuchi Y Burrow MF, Tagami J. Bond strengths to endodontically treated teeth. Am J Dent 1999; 12: 177-180.

35. Celik C, Erkut S, Gulsahi K, Yamanel K, Kucukesmen C. Effect of sodium ascorbate on bond strength of different adhesive sysytems to NaOCl-treated dentin. Aust Endod J 2010; 36:12-18.

36. Daumer KM, Khan AU, Steinbeck MJ. Chlorination of pyridinium compounds. Possible role of hypochlorite, n-chloramines, and chlorine in the oxidation of pyridinoline cross-links of articular cartilage collagen type II during acute inflammation. J Biol Chem 2000; 275:34681-92.

37. Choi K, Oshida Y, Platt JA, Cochran MA, Matis BA, Yi K. Microtensile bond strength of glass ionomer cement to artificially created carious dentin. Oper Dent 2006;31:590-7.

38. Hashimoto M, DE Munck J, Ito S, Sano H, Kaga M, Oguchi H. In vitro effect of nanoleakage expression on resin-dentin bond strengths analyzed by microtensile bond test, SEM/EDX and TEM. Biomaterials 2004; 25:5565-74.

39. Czarnecka B, Limanowska-Shaw H, Nicholson JW. Buffering and ion release by a glass-ionomer cement under near-neutral and acidic conditions. Biomaterials 2002; 23:2783-88.

40. Ngo H, Mount GJ, Peters MRCB. A study of glass ionomer cement and its interface with enamel and dentine using a low temperature, high resolution scanning electron microscopic technique. Quintessence Int. 1997; 28:63-9.

41. Ten Cate JM, Van Duinen RNB. Hypermineralization of dentinal lesions adjacent to glass-ionomer cement restorations. J Dent Res. 1995; 76:1266-71.

42. Islam SM, Hiraishi N, Nassar M, Sono R, Otski M, Takatsura $\mathrm{T}$. In vitro effect of hesperidin on root dentin collagen and de/re-mineralization. Dent Mater J 2012; 31:362-7. 